\title{
ACOlHimento institucional DE CRIANÇAS E ADOLESCENTES EM AraCAjU
}

\author{
SHELTER FOR CHILDREN AND ADOLESCENTS IN ARACAJU - BRAZIL \\ INSTITUCIONES QUE ALBERGAN NIÑOS Y \\ ADOLESCENTES EN ARACAJU - BRASIL
}

Fernanda Herminia Oliveira Souza*

Leila Maria Torraca de Brito**

\section{Resumo}

Este trabalho tem como objetivo apresentar e discutir pesquisas realizadas sobre a execução do acolhimento institucional de crianças e adolescentes em Aracaju, capital do estado de Sergipe (Brasil). Nas investigaçóes analisadas foi observado que as instituiçóes de acolhimento do município ainda náo cumprem todas as diretrizes propostas pelo Estatuto da Criança e do Adolescente para esse tipo de medida protetiva, o que acarreta violação de certos direitos das crianças e adolescentes. A análise desses trabalhos revela importantes problemas na execução do acolhimento institucional, tais como: desmembramento de grupo de irmãos no momento do acolhimento, instituiçôes que restringem o atendimento a crianças de determinada faixa etária, desarticulação da rede de proteçáo à infância e adolescência, significativo número de crianças e adolescentes do interior acolhidos na capital, ausência de trabalho com a família e dificuldades para efetivação do direito à convivência familiar e comunitária. Conclui-se pela necessidade de se oferecer modalidades de proteção à infância e à juventude que valorizem a família e evitem a aplicação da medida de acolhimento institucional.

Palavras-chave: criança e adolescente; abrigo; família.

\section{Abstract}

This paper aims to present and discuss researches conducted on the implementation of shelters for children and adolescent in Aracaju, capital of Ser-

\footnotetext{
* Universidade do Estado do Rio de Janeiro, Rio de Janeiro, RJ, Brasil.

** Universidade do Estado do Rio de Janeiro, Rio de Janeiro, RJ, Brasil.
} 
gipe (Brazil). It was observed on the analyzed surveys that Aracaju's shelters still do not carry out all of the guidelines proposed by the Statute of Children and Adolescents for this type of protective measure, which results in the violation of certain rights of children and adolescents. The analysis of these studies indicates problems in the implementation of shelters, such as: dismembering of siblings' group, shelters with age restrictions, communication problems of the network who protects childhood and adolescence, a significant number of children and adolescents born in the country side but sheltered in the capital, absence of work with children and adolescence's family, difficulties in ensuring the right to live among family members and community. We concluded that it is necessary to offer other ways of protecting children and adolescents in order to value the family and avoid the adoption of protective measure of sheltering.

Keywords: children and adolescent; shelter; family.

\section{RESUMEN}

Este trabajo tiene como objetivo presentar y discutir investigaciones sobre instituciones que albergan niños y adolescentes en Aracaju, capital del estado de Sergipe (Brasil). En las investigaciones analizadas se observó que las instituciones de ese condado aún no cumplen con todas las directrices propuestas por el Estatuto del Niño y del Adolescente para esto tipo de medida de protección, lo que resulta en la violación de determinados derechos de los niños y adolescentes. El análisis de estos estudios revela problemas importantes en la aplicación de la atención institucional como: desmembramiento de los hermanos en el momento de alberga miento; instituciones que restringen la asistencia a los niños de un determinado grupo de edad, la desarticulación de la red de seguridad para los niños y adolescentes, un número importante de niños y adolescentes de lo interior albergados en la capital, la falta de trabajo con la familia y las dificultades para garantizar el derecho a la vida familiar y comunitaria. Se concluye la necesidad de desarrollar otras formas de protección de los niños y jóvenes que valoran la familia y evitar la aplicación de la medida de alberga miento.

Palabras clave: niños y adolescentes; instituciones que albergan; familia. 
O Estatuto da Criança e do Adolescente (ECA, 1990) em seu art. 86 dispôe que "a política de atendimento dos direitos da criança e do adolescente far-se-á através de um conjunto articulado de ações governamentais e não governamentais, da União, dos estados, do Distrito Federal e dos municípios”. Destaca-se que uma das diretrizes para esse atendimento é a descentralização político-administrativa, ou seja, cada município passa a ter autonomia para desenvolver programas específicos destinados à sua população infanto-juvenil. Essa indicação permite que as especificidades locais sejam consideradas, rejeitando-se a ideia de um único modo de atuação em todo o território nacional. Dessa maneira, ainda que estados e municípios devam observar as diretrizes legais e as políticas públicas nacionais, podem desenvolver estratégias próprias que respondam às necessidades de suas crianças e adolescentes.

Nesse sentido, a fim de que planos de ação possam ser criados e implantados nos diferentes municípios brasileiros faz-se indispensável o mapeamento da situação local para que, a partir dos dados levantados, possam ser elaboradas estratégias de atuação. A descentralizaçáo político-administrativa pertinente à política de atendimento descrita no ECA (1990) também engloba as entidades destinadas ao acolhimento institucional de crianças e de adolescentes, tema que temos interesse em analisar neste trabalho, debruçando-nos especialmente sobre dados e informações referentes ao município de Aracaju (SE).

O ECA (1990) prevê no art. 98 medidas de proteção aplicáveis à criança e ao adolescente sempre que estes tiverem seus direitos ameaçados ou violados, seja por ação ou por omissão da sociedade ou do Estado, seja por falta, por ameaça ou por abuso dos pais ou responsáveis, ou ainda devido à conduta destes. Uma dessas medidas protetivas previstas na referida legislação é o acolhimento institucional (art. 101, inciso VII do ECA, 1990). Vale ressaltar que o termo abrigo, utilizado inicialmente no Estatuto da Criança e do Adolescente (1990) foi substituído, por meio da Lei 12.010 de 3 de agosto de 2009, por acolhimento institucional.

De acordo com o documento que reúne orientaçóes técnicas para o acolhimento, elaborado pelo Conselho Nacional dos Direitos da Criança e do Adolescente (CONANDA) e pelo Conselho Nacional de Assistência Social (CNAS) (2008), essa modalidade de atendimento consiste em um

Serviço que oferece acolhimento, cuidado e espaço de desenvolvimento para grupos de crianças e adolescentes em situação de abandono ou cujas famílias ou responsáveis encontrem-se temporariamente impossibilitados de cumprir sua função de cuidado e proteçáo. Oferece atendimento especializado e condiçôes institucionais para o acolhimento em padróes de 
dignidade, funcionando como moradia provisória até que seja viabilizado o retorno à família de origem ou, na sua impossibilidade, o encaminhamento para família substituta (p. 29).

No estudo do tema percebemos que pesquisas sobre o acolhimento institucional têm sido desenvolvidas em nosso país, especialmente nas regiōes Sul e Sudeste (Arpini, 2003; Rizzini, Rizzini, Naif, \& Baptista, 2007; Fávero, Vitale, \& Baptista, 2008; Siqueira \& Dell'Aglio, 2010; Rossetti-Ferreira, Serrano, \& Almeida, 2011; Rossetti-Ferreira et al., 2012; Arpini \& Siqueira, 2012; Siqueira, 2012), com vistas à compreensão do funcionamento dessas instituiçóes e à discussão de propostas para o desenvolvimento, implantação e gestão de políticas públicas. Esses estudos visam também ao aperfeiçoamento de práticas por meio da análise de estratégias de atuação no campo institucional. Investigaçôes sobre essa mesma temática também têm sido realizadas na região Nordeste do país, apesar de em menor número e de contarem com menos visibilidade. Dentre elas destacam-se aquelas realizadas por Tavares (2005), Souza (2009) e por Lima e Berger (2011).

No que diz respeito ao acolhimento institucional de crianças em Aracaju, capital de Sergipe (SE), menor estado do Brasil, cabe ressaltar que recentemente foram ajuizadas pelo Ministério Público/SE duas açóes civis públicas (Ferreira, 2012a; Ferreira, 2012b; Melo, 2008) em razão da constatação do número insuficiente de programas de proteção para crianças e adolescentes e da inexistência de políticas de atendimento adequadas. O Município de Aracaju ainda não oferecia, em 2012, serviço de acolhimento institucional para todas as faixas etárias dentro dos princípios estabelecidos pelo art. 92 do ECA (1990), nem a modalidade casa lar. Também não oferecia programa de acolhimento familiar, nem programa para egressos. Essas ações impetradas pelo Ministério Público/SE revelam tanto uma preocupaçáo com o acolhimento institucional na localidade, quanto um descompasso entre os problemas destacados e as diretrizes legais, o que evidencia dificuldades na execução das normativas presentes na lei que versa sobre a proteção integral à criança e ao adolescente em nosso país, o ECA (1990).

Observamos, todavia, que em data anterior às açóes impetradas pelo Ministério Público/SE já haviam sido realizadas investigaçôes que visavam analisar especificamente o funcionamento dessas instituiçóes em Aracaju (Tavares, 2005; Souza, 2009) bem como pesquisa nacional que contemplou a regiâo Nordeste e a referida capital (Silva, 2004). Por esse motivo, com a proposta de contribuir com uma análise panorâmica sobre a execução do acolhimento institucional naquele município reunimos, neste trabalho, dados de pesquisas que fornecem informa- 
çóes sobre a condução dessa medida protetiva na localidade. Buscamos, assim, circunscrever possíveis causas no funcionamento das instituiçóes de acolhimento que contribuíram para as ações impetradas pelo Ministério Público do Estado de Sergipe.

Acreditamos que o material aqui exposto poderá servir de subsídio para as prováveis e necessárias modificações no atendimento às crianças e adolescentes que estão sob medida protetiva de acolhimento institucional em Aracaju, como também poderá contribuir com a discussão da temática em outras regiōes do país. Consideramos que a reunião de informaçóes sobre a situação do acolhimento institucional no citado município facilita a divulgação de pesquisas já realizadas, bem como um apurado exame dos dados obtidos.

\section{Panorama do acolhimento institucional em Aracaju}

Inicialmente cabe esclarecer que neste item utilizaremos o termo abrigo e não acolhimento institucional, tendo em vista que a alteração da nomenclatura aconteceu em 2009, portanto em data posterior à publicação das pesquisas que aqui serão exploradas.

Apresentaremos dados relativos ao levantamento, realizado em âmbito nacional, pelo Instituto de Pesquisa Econômica e Aplicada (IPEA) intitulado "O direito à convivência familiar e comunitária: os abrigos para crianças e adolescentes no Brasil" (Silva, 2004) que buscou conhecer as características, a estrutura de funcionamento e os serviços prestados por abrigos dos diferentes estados brasileiros entre 2001 e 2004. Apesar de a pesquisa ter sido divulgada na mídia e citada por alguns autores consideramos que dados referentes ao Nordeste, especificamente ao estado de Sergipe, podem ser recortados desse amplo trabalho para uma análise mais detida.

No levantamento organizado por Silva (2004) foram avaliados os estabelecimentos beneficiados com recursos do Governo Federal repassados por meio da Rede de Serviços de Ação Continuada (Rede SAC) do Ministério do Desenvolvimento Social. Esse material oferece extensa informação sobre a situação dos abrigos no Brasil sendo utilizado, inclusive, como subsídio para as discussóes que resultaram na elaboração do Plano Nacional de Promoção, Proteção e Defesa do Direito de Crianças e Adolescentes à Convivência Familiar e Comunitária (2006). A estruturação desse Plano teve como finalidade dar prioridade à temática da convivência familiar com vistas à formulação e implantação de políticas públicas que garantam os direitos de crianças e de adolescentes. 
No relatório apresentado pelo IPEA (Silva, 2004) há esclarecimentos de que foram pesquisadas $88 \%$ das instituiçóes atendidas pela Rede SAC, o que correspondia, naquele período, a 589 abrigos. Destes, a maioria estava localizada na região Sudeste $(49,1 \%)$, seguida pela região Sul $(20,7 \%)$ e pela região Nordeste $(19,0 \%)$. No estudo em apreço o estado de Sergipe foi contemplado na análise e contava, na época, com 12 abrigos atendidos pela rede SAC, responsáveis por 410 crianças e adolescentes.

No que diz respeito à distribuição dos abrigos segundo a natureza institucional, dados divulgados naquele mesmo relatório (Silva, 2004) apontaram que no Nordeste $65,2 \%$ das intituições pesquisadas eram não governamentais, $10,7 \%$ municipais e $24,1 \%$ estaduais, evidenciando que a municipalização da política de atendimento ainda não era preponderante na região.

Em relação à faixa etária atendida, encontramos a informação de que no Brasil

entre as crianças e os adolescentes abrigados na época de realização desta pesquisa, 11,7\% tinham de zero a 3 anos; $12,2 \%$, de 4 a 6 anos; 19,0\%, de 7 a 9 anos; $21,8 \%$, de 10 a 12 anos; 20,5\%, de 13 a15 anos; e 11,9\% tinham entre 16 e 18 anos incompletos. Vale registrar que, apesar da medida de abrigo se aplicar apenas à populaçáo menor de 18 anos, 2,3\% dos pesquisados tinham mais de 18 (Silva, 2004, p. 48).

Sobre os motivos que levaram ao abrigamento de crianças e adolescentes, a pesquisa do IPEA relata que a principal alegaçáo encontrada nos diversos estados foi a carência de recursos materiais da família, resposta fornecida por $24,1 \%$ de todo o contingente pesquisado. No Nordeste, essa foi a resposta dada por 34,3\% das instituiçôes estudadas. A mesma pesquisa apontou que $87 \%$ das crianças e adolescentes que estavam nos estabelecimentos dos diversos estados possuíam família, sendo que 58,2\% mantinham contato com seus familiares por meio de visitas periódicas destes às instituições. No Nordeste, $64,3 \%$ das crianças e dos adolescentes abrigados mantinham contato com membros da rede familiar.

Sobre o tempo de abrigamento, os dados coletados pelo IPEA revelaram que $52,6 \%$ das crianças e dos adolescentes pesquisados no país estavam abrigados há mais de dois anos. Além disso, 20,9\% dos abrigados estavam fora de seus municípios de origem. No Nordeste, a porcentagem de crianças e de adolescentes abrigados fora de seu município era de 19,2\%. Ainda no que diz respeito à regiáo Nordeste, $57,2 \%$ das instituiçóes pesquisadas realizavam seu atendimento pela divisão masculino/feminino, enquanto a média nacional era de $37,2 \%$ (Silva, 2004). 
Quase na mesma época do levantamento feito pelo IPEA foi organizada por Tavares (2005) uma pesquisa em Sergipe com o objetivo de levantar informaçóes acerca das instituições que abrigavam crianças e adolescentes, registradas no Conselho Municipal Dos Direitos da Criança e do Adolescente da localidade. Esse trabalho foi motivado pela constataçáo, por parte de membros do Conselho Municipal de Direitos da Criança e do Adolescente de Aracaju e de representantes do Ministério Público do Estado de Sergipe, de problemas nas práticas institucionais. Dentre as problemáticas observadas podemos destacar o desconhecimento por parte dos funcionários dos abrigos dos procedimentos necessários para o abrigamento de crianças e adolescentes e das responsabilidades institucionais, ausência de profissionais para executar certas tarefas nas unidades - determinados trabalhos eram realizados pelos adolescentes abrigados -, inexistência de acompanhamento psicossocial à família, bem como de programação de lazer e de estímulos à convivência familiar. Também não existia preparo para o desligamento dos internos e para o acompanhamento de egressos.

De acordo com a descriçáo da pesquisa organizada por Tavares (2005), desde 2004 o Ministério Público do Estado de Sergipe vinha se manifestando sobre as inadequadas condiçóes dos estabelecimentos que ofereciam serviços de abrigo em Aracaju. A autora também notou que a maioria dos abrigos atuava em descompasso com as diretrizes do ECA (1990), especialmente em relação ao número elevado de crianças e adolescentes, sendo que oito das doze instituições que investigou descumpriam a orientação de atendimento em grupos reduzidos. Além disso, quase não havia atendimento personalizado. Predominava o abrigamento de grupos homogêneos no que diz respeito à faixa etária e ao sexo, o que resultava na separaçáo de irmãos.

O perfil das crianças e adolescentes abrigados variava, na época, ainda segundo Tavares (2005), desde idade inferior a um ano até mais de dezoito anos. Dos 316 abrigados na capital, 52,2\% eram de Aracaju e 17\% provenientes de outros municípios sergipanos. Isso significa que, como também verificado na pesquisa conduzida pelo IPEA (Silva, 2004), crianças do interior eram abrigadas na capital, o que contraria o direito à convivência familiar e comunitária, uma vez que a distância geográfica e ausência de recursos materiais para custear transporte dificultam a comunicação entre a criança/adolescente e sua família e comunidade de origem. Os dados coletados por Tavares (2005) revelaram que 37,3\% das crianças e adolescentes abrigados em Aracaju não recebiam visitas. Dentre os que recebiam, 26,9\% eram visitados apenas pela máe, 5,1\% somente pelo pai e 7,6\% por ambos.

Quanto ao tempo de abrigamento, a citada investigaçáo constatou que $35,1 \%$ das crianças e dos adolescentes encontravam-se há menos de um ano na 
instituição, 23,4\% há um ano, 13,9\% há dois anos, 5,7\% há três anos e 4,7\% por cinco anos. No que concerne aos motivos que levaram ao abrigamento, os prontuários analisados demonstraram que "das 316 crianças e adolescentes abrigados, 15,8\% tem como motivação a miséria e dificuldade financeira do grupo familiar" (Tavares, 2005, p. 34). Esse mesmo dado foi encontrado na pesquisa do IPEA (Silva, 2004), a qual descreve a carência de recursos materiais da família como principal razão para o abrigamento de crianças e de adolescentes em todo o Brasil. Outras justificativas para o ingresso no abrigo, em Aracaju, foram: negligência familiar, situação de risco, maus tratos, abandono, situação de rua, conflito familiar, abuso sexual, pais dependentes químicos, orfandade e trabalho infantil. Em alguns casos não havia registro do motivo. Vale ressaltar que, de acordo com o ECA (1990), a falta de recursos materiais não deve ser condição para afastar a criança da família.

A pesquisa organizada por Tavares (2005) revelou, em primeiro plano, uma aparente dificuldade das instituiçóes para seguir as diretrizes do ECA (1990), incluindo-se aí o caráter excepcional e provisório do abrigamento. Em segundo plano, a não efetivação de um dos direitos das crianças e adolescentes: o direito à convivência familiar e comunitária. Isto indica que açóes devem ser realizadas a fim de que as determinações do Estatuto sejam cumpridas e as instituições de acolhimento possam ser de fato lugar de passagem e não de permanência.

Um pouco depois, no ano de 2008, Souza (2009) realizou pesquisa em Aracaju (SE) com o objetivo de descrever o funcionamento dos abrigos com base no discurso de seus funcionários. A partir do relato daqueles que atuavam nestas instituições, a autora buscou compreender o atendimento prestado à população infanto-juvenil abrigada no município. A análise pretendeu averiguar tanto se a rede de proteção à infância e à adolescência conseguia se articular, quanto entender se a rotina dos estabelecimentos se adequava ao disposto no Estatuto da Criança e do Adolescente (1990).

Souza (2009) efetuou pesquisa em quatro abrigos daquele município sendo dois governamentais (um masculino e um feminino) e dois não governamentais (um masculino e um feminino). Na época, Aracaju contava com onze instituiçóes que eram responsáveis por, aproximadamente, 210 crianças e adolescentes. Para fins da investigação, foram entrevistados o coordenador e um funcionário de cada instituição, totalizando três coordenadores e quatro funcionários. Os resultados da pesquisa evidenciaram que a rede de proteção à infância e à adolescência, no ano analisado, ainda estava sendo tecida e apresentava lacunas no atendimento, como relatou um coordenador de abrigo governamental masculino: 
Há quatro anos atrás, quando eu estava entrando na questão de abrigos, da proteção de crianças e adolescentes, a gente estava falando na formaçáo de uma rede, hoje, o discurso da própria rede é que essa rede está furada ou que náo existe... acho que a gente tem alguns problemas, mas a rede, ela existe, os equipamentos sociais necessários ao suporte desse público, eles existem. O que falta é as pessoas se verem, enquanto rede (Souza, 2009, p. 31-32).

A inexistência de uma rede coesa que trabalhe como protetora da infância e da adolescência demonstra a diferença entre o que está previsto na lei e a realidade dos abrigos. Os funcionários das instituiçóes pesquisadas, componentes da rede, percebiam que ela não oferecia suporte, descrevendo-a como "furada", portanto com necessidade de ser reavaliada. As explicaçóes encontradas pelos entrevistados para as dificuldades do funcionamento da rede apareceram ora atreladas às práticas profissionais, ora à ausência de políticas públicas, como podemos observar na entrevista de um funcionário de instituição governamental masculina: "Existem muitas pessoas, a nível de internação, bem intencionadas. Mas infelizmente considero um pouco defasada a questáo estadual, tem gente que quer, que tem boa vontade, mas eu acho que ainda falta algo" (Souza, 2009, p. 33).

Com o intuito de compreender como se dava o ingresso de crianças e adolescentes nos abrigos, Souza (2009) questionou de que modo ocorria a recepção das crianças, quais os motivos para o ingresso e qual era a rotina da instituição. Destacamos trecho da fala de uma coordenadora de abrigo governamental feminino:

Se for a gente que recebe, a gente tem uma primeira conversa com o órgão de abrigamento... porque geralmente as pessoas veem o abrigamento como primeira instância, como primeiro recurso mesmo, então assim, até para a gente saber se aquela adolescente, aquela criança já passou por algum programa de auxílio e qual é a verdadeira situação pra ver se a gente consegue tirar alguma coisa, porque as vezes o que eles informam de motivo de abrigamento não é a real situação. E aí a gente tira aquela criança e adolescente da sua comunidade, da sua família e traz para um abrigo quando não é nada daquilo que aquela adolescente está precisando... aí a gente tem uma conversa com a criança ou com o adolescente... pergunta se eles sabem o que é o abrigo, informa o que é, as vezes elas vem muito apreensivas porque acham que estão sendo castigadas e a gente explica que não é nada disso, que isso é um programa como qualquer outro... (Souza, 2009, p. 37). 
No tocante à recepção de crianças e adolescentes, Souza (2009) afirma que os entrevistados se referiram a duas formas de ingresso no abrigo: abrigamento "não-forçoso" e abrigamento "forçoso". De acordo com o discurso do coordenador de uma instituição governamental masculina estudada por aquela autora, quando a criança ou o adolescente ingressava na instituição porque a família não conseguia garantir seus direitos e o Estado precisava intervir, o abrigamento se dava de maneira "não-forçosa" e não era entendido como castigo. Já o abrigamento que ocorria como punição, que se daria pela prática do ato infracional, seria o "forçoso". Esse coordenador entrevistado afirmou ainda que, em Aracaju, estavam abrigados na mesma instituição tanto crianças e adolescentes que cometeram ato infracional, quanto os que não o praticaram. Esse fato ocorria tanto pelo encaminhamento efetuado, que confundia proteção e socioeducação, como pela carência de instituiçóes específicas para as diferentes modalidades de atendimento.

Todas as instituiçóes estudadas por Souza (2009) possibilitavam visitas diárias de familiares, ou de qualquer cidadão, com exceção daqueles proibidos por lei. De acordo com aquela pesquisa os abrigos pareciam entender que essa seria uma maneira de promover a reinserção familiar. Questionamos, todavia, se a permissão de visitas dos familiares à instituição, sem restrições, promoveria a reinserção familiar e comunitária. Acreditamos que a possibilidade de visita de membros da família aos abrigos, salvo aqueles impedidos judicialmente, deve ser não só permitida como incentivada, entretanto somente a visita não garante nem promove a convivência familiar e comunitária, uma vez que é preciso tentar reverter os problemas que acarretaram a aplicação da medida protetiva de abrigo. Além disso, não podemos desprezar o fato de que muitos familiares encontram dificuldades para se dirigir ao estabelecimento onde estáo seus filhos por motivos diversos, dentre eles a impossibilidade financeira para custear o deslocamento. Assim, além das visitas, devem ser realizadas outras açóes de promoção da reintegração familiar.

\section{Discutindo sobre o acolhimento institucional em Aracaju}

Como exposto anteriormente, um dos motivos para a realização do estudo organizado por Tavares (2005) foi a percepção, pelo Ministério Público Estadual, do escasso conhecimento dos funcionários tanto a respeito dos procedimentos necessários para o abrigamento, quanto das responsabilidades institucionais dispostas no ECA (1990). Três anos depois parece que pouco investimento foi realizado, uma vez que outra pesquisa feita em Aracaju (Souza, 2009) encontrou os 
mesmos problemas no que diz respeito ao caráter provisório e à excepcionalidade de aplicação dessa medida, situaçáo que se mantinha em desacordo com o art. $101 \$ 1^{\circ}$ do ECA (1990). Como previsto na lei, o acolhimento institucional, além de não implicar na privação de liberdade, deve ter como finalidade a reintegração familiar, ou a colocação em família substituta. A transitoriedade da medida não deve ser menosprezada.

Quanto ao tempo de permanência no acolhimento, o ECA (1990) dispóe, no artigo $19 \$ 2$, qu: "a permanência da criança e do adolescente em programa de acolhimento institucional não se prolongará por mais de 2 (dois) anos, salvo comprovada necessidade que atenda ao seu superior interesse, devidamente fundamentada pela autoridade judiciária”. Cabe ressaltar, entretanto, que essa redação do Estatuto passou a vigorar apenas em agosto de 2009, com as modificaçóes feitas pela Lei 12.010 (2009). Na época de realização das pesquisas anteriormente citadas (Silva, 2004; Tavares, 2005; Souza, 2009) essa alteração ainda não havia ocorrido, sendo possível verificar que o tempo de abrigamento das crianças e dos adolescentes extrapolava a permanência de dois anos.

Cabe ressaltar que o direito de conviver com a família e a comunidade é resguardado pela Constituição Federal (1988) a todas as crianças e adolescentes, inclusive os que estão acolhidos institucionalmente, pois, ainda que estejam afastados de suas famílias, devem-se envidar esforços para a reintegração familiar. É preciso refletir como preservar esse direito em um ambiente institucional, uma vez que a convivência familiar e comunitária é uma conquista que, apesar de estar incluída na legislação, ainda encontra dificuldades para ser executada. Entendemos que o trabalho de reinserçáo familiar e comunitária deve ser realizado para além dos muros do abrigo, através dos braços do sistema de garantia de direitos, alcançando as famílias por meio da execução das políticas públicas.

Rizzini et al. (2007) explicam que no Brasil há uma lacuna entre a importância atribuída ao papel da família no discurso do poder público e a falta de condiçóes mínimas de vida digna que esta enfrenta. Essas mesmas autoras, em estudo realizado sobre as experiências de promoção do direito à convivência familiar e comunitária no Brasil, descrevem problemas que permeiam esse direito, dentre eles: a persistência de um modelo assistencialista que mantém a população na pobreza, sendo refém de políticas clientelistas que justificam a constante intervenção sobre os pais e seus filhos. As autoras também destacam que muitas dificuldades pelas quais as organizaçóes familiares passam não são interpretadas como violaçóes de direitos por parte do Estado, mas como sendo falhas do próprio núcleo familiar. Notaram, ainda, falta de articulação e de clareza de atribuiçóes dos aparatos de apoio às famílias, tal como concluíram as pesquisas realizadas em Aracaju. 
Podemos observar que em normativas legais como no Estatuto da Criança e do Adolescente, (1990), no Plano Nacional de Promoção, Proteção e Defesa do Direito de Crianças e Adolescentes à Convivência Familiar e Comunitária (2006) e na Lei 12.010 (2009), a família aparece em primeiro plano, no centro das açôes voltadas à proteção da infância e da adolescência. Entretanto, é possível questionar quem estaria cuidando dessas famílias. O que lhes é ofertado pelas políticas públicas para que possam voltar a se responsabilizar por suas crianças e adolescentes?

Acreditamos, assim, que é preciso estar atento ao que Rossetti-Ferreira $e t$ al. (2012, p. 394) chamam de "invisibilidade da família", termo que na pesquisa por elas desenvolvida expressa o desconhecimento ou a ausência de informaçóes básicas sobre a organização familiar e seus membros, por exemplo: idade, escolaridade, profissão, encaminhamentos para programas de apoio, entre outros. As autoras argumentam que existem poucas açóes para a manutenção e (re)construção dos vínculos afetivos no contexto familiar, além da ausência de mecanismos que promovam a participação da família no cotidiano da instituição. Levando em conta a "invisibilidade da família" descrita por Rossetti- Ferreira et al. (2012), e considerando os dados levantados por Souza (2009) podemos questionar o que alguns funcionários das instituiçóes de acolhimento de Aracaju entendem como reinserção familiar e comunitária e como trabalham a provisoriedade da medida na rotina institucional.

Como já exposto, entendemos que a promoção da reinserção familiar e comunitária requer mais do que a permissão para a família visitar suas crianças e adolescentes. É preciso que diversas açóes sejam empreendidas com os familiares daqueles que estão sob a medida protetiva de acolhimento institucional para que eles possam conseguir recursos a fim de ter seus filhos consigo novamente. Incluir os familiares em programas de auxílio e incentivá-los a participar de atividades oferecidas pela instituição, além do dia da visita, pode ser uma estratégia. Ademais, o acompanhamento das famílias por equipes, ou ainda, propostas de atendimento terapêutico podem ser alternativas necessárias.

Destacamos abaixo experiência realizada na França que pode servir para pensarmos em práticas alternativas ao acolhimento em instituiçốes e modos de atuação para o trabalho com a família com vistas à promoção do direito à convivência familiar e comunitária. Não se trata de importar o modelo francês para nosso país, tampouco de negligenciar experiências positivas realizadas no Brasil, mas de analisar diferentes modos de atuaçáo que evitem o ingresso na instituição como primeira opção para resoluçáo de problemas. Ainda que na literatura existam pesquisas que descrevem trabalhos de reinserção familiar e comunitária, 
eles são realizados após o acolhimento, carecendo de propostas alternativas que possam ser utilizadas no lugar dessa medida.

Em leitura do guia francês de proteção à infância intitulado "L'accueil de l'enfant et de l'adolescent protégé ${ }^{1 "}$ (Ministério da Saúde e da Solidariedade da França, 2011), pudemos compreender os novos dispositivos de proteção e as recentes modalidades de acolhimento oferecidas, de acordo com a lei de 5 de março de 2007 (França, 2007), que reformou a proteção à infância naquele país. O trabalho por eles proposto tem como prioridade o desenvolvimento de açóes com a criança e com sua família, sendo recomendado acompanhamento sistemático com a família quando esta se encontra com dificuldades no exercício da autoridade parental e na educação de seus filhos. Esse acompanhamento acontece tanto quando a criança ou adolescente ainda estão em seu domicílio, como quando já se encontram em instituiçóes. A referida publicação ressalta a importância de a família ser assistida, pois se considera que ela também deve ser alvo de atenção para que possa ser auxiliada a dirimir os problemas que levaram seus filhos a necessitar de proteção administrativa ou judiciária. Notamos, portanto, que no contexto francês há preocupação de se explicar às famílias que as modalidades de cuidado oferecidas à criança e ao adolescente na instituição visam a promover ajuda aos familiares para que possam superar suas dificuldades reconstruindo os recursos parentais. Além disso, procura-se que os responsáveis tenham clareza do trabalho que está sendo realizado com as crianças ou adolescentes como também do objetivo a ser alcançado, salientando a relevância de a família participar desse processo (Ministério da Saúde e da Solidariedade da França, 2011).

Os dispositivos de acolhimento descritos no guia francês oferecem apoio à família e às crianças e adolescentes por meio de modalidades diversas que incluem, por exemplo: a oferta de acolhimento-dia para crianças e adolescentes de qualquer idade que podem passar o dia na instituição e ir para casa à noite. Os acolhimentos modulados, o periódico ou o excepcional, se apresentam como formas alternativas entre a manutenção da criança em seu domicílio e a colocação em outro ambiente. Essas três modalidades permitem uma flexibilidade ao dispositivo de proteção, pois possibilitam respostas gradativas às diversas situaçóes em que se encontram crianças, adolescentes e suas famílias. $\mathrm{O}$ acolhimento modulado permite, com a anuência dos pais, combinar a manutenção no domicílio com um acolhimento por sequências, fora do ambiente familiar. Os acolhimentos periódico e excepcional são modalidades de ação educativa com predominância em meio aberto. $\mathrm{O}$ primeiro alterna tempos de acolhimento na instituição e tempos na família, pode servir tanto para preparar o ingresso na instituição (ou seja, tendo sido constatada a necessidade de acolhimento no lugar de retirar a criança 
ou o adolescente de sua casa de modo abrupto pode-se usar essa modalidade), quanto para preparar o retorno ao ambiente familiar e comunitário. O segundo trata de acolhimento pelo serviço educativo por um período limitado. Percebemos, dessa forma, a preocupação de estar ofertando diferentes modalidades de ajuda à família e de proteção à criança e ao adolescente que não se restrinjam ao acolhimento institucional.

\section{Consideraçóes finais}

A análise sobre o acolhimento institucional realizada a partir dos dados divulgados, tanto pela pesquisa nacional realizada pelo IPEA (Silva, 2004), quanto pelas investigaçóes desenvolvidas em Aracaju por Tavares (2005) e por Souza (2009), nos permite concluir que existem significativas dificuldades na execução dessa medida: falta de articulação da rede de proteção à infância e adolescência, existência de instituições que atuam pela divisão sexo/faixa etária, expressivo número de crianças e adolescentes do interior acolhidos na capital, ausência de um trabalho efetivo de reintegração familiar e comunitária e inexistência de atividades junto à família. Esse último fato é visto como uma das principais dificuldades para a efetivação do direito à convivência familiar e comunitária e a consequente extinção da medida de acolhimento institucional.

As informaçóes dispostas nas pesquisas desenvolvidas por Tavares (2005) e por Souza (2009) conduzem à suposição de que as açóes civis públicas impetradas pelo Ministério Público do Estado de Sergipe seriam consequências das condições observadas ao longo dos últimos anos nas agora denominadas instituiçóes de acolhimento para crianças e adolescentes. $\mathrm{O}$ ajuizamento dessas açóes, alegando problemas também descritos nas citadas pesquisas, especialmente o descompasso entre as diretrizes do ECA (1990) e o funcionamento dessas instituiçóes indica que os esforços para melhoria do acolhimento institucional em Aracaju/Sergipe têm acontecido a passos lentos, com poucas mudanças no período analisado. Desse modo, acreditamos que investimentos precisam ser realizados tanto pelo estado quanto pelo município a fim de melhorar o funcionamento dessas instituições em Aracaju/SE. As ações precisam ter como foco também um direito esquecido ou pouco explorado: o direito à convivência familiar e comunitária.

Destacamos a experiência francesa como uma possibilidade de conhecer novas práticas e a partir delas desenvolver açôes que proporcionem modificaçóes no ambiente institucional e na rede de proteção à infância e a adolescência com o objetivo de garantir a convivência familiar e comunitária de crianças e adolescen- 
tes. Com essa afirmação não estamos desconsiderando que alguns autores tenham apontado na literatura experiências exitosas no Brasil, mas sim ressaltando que um olhar diferenciado pode contribuir com novas perspectivas.

Por conseguinte, para a efetivação do direito à convivência familiar e comunitária de crianças e adolescentes acolhidos institucionalmente é preciso que sejam avaliadas as dificuldades atuais das famílias, oferecendo dispositivos de acolhimento que estejam de acordo com suas necessidades, inserindo-as nesse processo e ajudando-as a entender as medidas aplicadas, a exemplo do que vem sendo feito no contexto francês.

Conclui-se pela necessidade de pensar e desenvolver outras modalidades de proteção à infância e juventude que valorizem a família e evitem a aplicação do acolhimento institucional como primeira opção de medida de proteção. Compreendemos que outras pesquisas devem ser realizadas explorando a dinâmica de trabalho existente, mapeando problemas e soluçôes encontradas. Dessa maneira será possível contribuir para a melhoria das políticas públicas voltadas para o ordenamento e o financiamento dos serviços destinados a crianças e adolescentes de acordo com as diretrizes tanto do Estatuto da Criança e do Adolescente (1990) como da lei 12.010 de 2009 que "dispóe sobre o aperfeiçoamento da sistemática prevista para a garantia do direito à convivência familiar a todas as crianças e adolescentes, na forma prevista pela lei no 8.069, de 13 de julho de 1990, Estatuto da Criança e do Adolescente" (art. 10).

\section{Referências}

Arpini, D. M. (2003). Repensando a perspectiva institucional e a intervenção em abrigos para crianças e adolescentes. Psicologia Ciência e Profissäo, 21(3), 70-75.

Arpini, D. M., \& Siqueira, A. C. (2012). Psicologia, famílias e leis: desafios à realidade brasileira. Santa Maria: Editora UFSM.

Brasil (1988). Constituição da República Federativa do Brasil de 1988. Recuperado em 14 jun., 2009, de <http://www.planalto.gov.br/ccivil_03/constituicao/constituicaocompilado.htm>. Brasil (1990). Estatuto da criança e do adolescente. Lei no 8.069, de 13 de julho de 1990. Brasília, DF: Autor. Recuperado em 14 ago., 2012, de <http://www.planalto.gov.br/ccivil_03/Leis/ L8069.htm>.

Brasil (2006). Plano Nacional de Promoção, Proteção e Defesa do Direito de Crianças e Adolescentes à Convivência Familiar e Comunitária. Brasília, DF: CONANDA.

Brasil (2008). Orientaçóes técnicas para os serviços de acolhimento para crianças e adolescentes. Brasília, DF: CONANDA/CNAS. 
Brasil (2009). Lei no 12.010, de 3 de agosto de 2009. Brasília, DF: Autor. Recuperado em 14 set., 2010, de <http://www.planalto.gov.br/ccivil_03/_Ato2007-2010/2009/Lei/L12010. htm>.

Fávero, E. T., Vitale, M. A. F., \& Baptista, M. V. (2008). Famílias de crianças e adolescentes abrigados - quem são, como vivem, o que pensam, o que desejam. São Paulo: Paulus.

Ferreira, H. (2012a). MP requer tratamento especializado para adolescente em situação de risco social. Recuperado em 14 ago., 2012, de <http://www.lagartense.com.br/11396/ mp-requer-tratamento-especializado-para-adolescente-em-situacao-de-risco-social>.

Ferreira, H. (2012b). Estado e município seráo obrigados a ressarcir dano moral e material a adolescentes em situação de risco. Recuperado em 14 ago., 2012, de <http://www.imprensa1. com.br/?p=623>.

França (2007). Loi n ${ }^{\circ}$ 2007-293 du 5 mars 2007 réformant la protection de l'enfance (1). França: Autor. Recuperado em 04 set., 2013, de <http://www.legifrance.gouv.fr/affichTexte.do ?cidTexte=JORFTEXT000000823100.

Lima, S. S., \& Berger, M. A. A. (2011). Casa Maternal Amélia Leite (1947-1970) - Uma instituição educativa de proteção à maternidade e à infância. Cadernos de História da Educação, 10(2), 315-325.

Melo, R. (2008). Ministério Público Estadual ajuiza Ação contra a Fundação Renascer. Recuperado em 14 ago. 2012, de < http://mp-se.jusbrasil.com.br/noticias/959486/ ministerio-publico-estadual-ajuiza-acao-contra-a-fundacao-renascer>.

Ministério da Saúde e da Solidariedade da França. (2011). L'accueil de l'enfant et de l'adolescent protégé. Recuperado em 04 set., 2013, de <http://www.social-sante.gouv.fr/IMG/pdf/Guide_Accueil_3_BAT-3.pdf>.

Rizzini, I., Rizzini, I., Naif, L., \& Baptista, R. (2007). Acolhendo crianças e adolescentes: experiências de promoção do direito à convivência familiar e comunitária no Brasil. São Paulo: Cortez Editora.

Rossetti-Ferreira, M. C., Serrano, A. S., \& Almeida, I. G. (2011). O acolhimento institucional na perspectiva da criança. São Paulo: Hucitec Editora.

Rossetti-Ferreira, M. C., Almeida, I. G., Costa, N. R. A., Guimarães, L. A., Mariano, F. N., Teixeira, S. C. P., \& Serrano, S. A. (2012). Acolhimento de crianças e adolescentes em situaçôes de abandono, violência e rupturas. Psicologia: Reflexão e Crítica, 25(2), 390-399.

Silva, E. R. (2004). O direito à convivência familiar e comunitária: os abrigos para crianças e adolescentes no Brasil. Brasília: Ipea/Conanda.

Siqueira, A. C., \& Dell'aglio, D. D. (2010). Crianças e adolescentes institucionalizados: desempenho escolar, satisfação de vida e rede de apoio social. Psicologia: Teoria e Pesquisa, 26(3), 407-415.

Siqueira, A. C. (2012). A garantia ao direito à convivência familiar e comunitária em foco. Estudos de Psicologia (Campinas), 29(3), 437-444. 
Souza, F. H. O. (2009). Um olhar sobre o abrigamento de crianças e adolescentes. (Trabalho de conclusão de curso de graduação. Departamento de Psicologia. Universidade Federal de Sergipe, São Cristóvão, SE).

Tavares, M. (2005). Crianças e adolescentes em situação de abrigo: um retrato em branco e preto. Aracaju: Infographics.

\section{Notas}

1 "O Acolhimento da criança e do adolescente protegido": <http://www.social-sante.gouv.fr/ IMG/pdf/Guide_Accueil_3_BAT-3.pdf>.

Recebido em 11 de outubro de 2013 Aceito para publicação em 01 de junho de 2014

DOI: 10.1590/0103-56652015000100003 
